\title{
Transmission and Institutional Infection Control of Tuberculosis
}

\author{
Edward A. Nardell \\ Division of Global Health Equity, Brigham \& Women's Hospital, Boston, Massachusetts 02115 \\ Correspondence: ean@hsph.harvard.edu
}

\begin{abstract}
Tuberculosis (TB) transmission control in institutions is evolving with increased awareness of the rapid impact of treatment on transmission, the importance of the unsuspected, untreated case of transmission, and the advent of rapid molecular diagnostics. With active case finding based on cough surveillance and rapid drug susceptibility testing, in theory, it is possible to be reasonably sure that no patient enters a facility with undiagnosed TB or drug resistance. Droplet nuclei transmission of TB is reviewed with an emphasis on risk factors relevant to control. Among environmental controls, natural ventilation and upper-room ultraviolet germicidal ultraviolet air disinfection are the most cost-effective choices, although high-volume mechanical ventilation can also be used. Room air cleaners are generally not recommended. Maintenance is required for all engineering solutions. Finally, personal protection with fittested respirators is used in many situations where administrative and engineering methods cannot assure protection.
\end{abstract}

\section{HOW TUBERCULOSIS IS TRANSMITTED}

Uncontrolled transmission is fueling the global tuberculosis (TB) epidemic (Bacaër et al. 2008). Although some transmission probably occurs out of doors, it is believed to be less likely primarily because of infinite dilution of infectious droplet nuclei in air. Transmission occurs more efficiently indoors where dilution is limited and occupants are concentrated. All indoor environments are potential sites of transmission, most importantly, homes and congregate settings such as hospitals, clinics, refugee camps, factories, homeless shelters, prisons, and many more, including most modes of transportation (Middelkoop et al. 2008; Johnstone-Robertson 2011a,b). Tuberculosis is al- most exclusively airborne because initially it is usually an infection of the alveolar macrophage (Ordway et al. 2006; Orme 2014). To reach macrophages in the far reaches of the lung, inhaled particles in the 1 to $5 \mu \mathrm{m}$ range are requiredsmall enough to remain suspended indefinitely and to follow room air currents. Droplet nuclei are the dehydrated residua of larger respiratory droplets generated by patients with pulmonary or laryngeal TB who are coughing or otherwise generating aerosol (Riley 1974). These dried respirable particles are small enough to accommodate one or at most a few tubercle organisms (Riley 1957). Infectious aerosols are also generated in TB laboratories when concentrated specimens are processed, and occasionally by other means, such as the irrigation of wounds,

Editors: Stefan H.E. Kaufmann, Eric J. Rubin, and Alimuddin Zumla

Additional Perspectives on Tuberculosis available at www.perspectivesinmedicine.org

Copyright (C) 2016 Cold Spring Harbor Laboratory Press; all rights reserved; doi: 10.1101/cshperspect.a018192

Cite this article as Cold Spring Harb Perspect Med 2016;6:a018192 
E.A. Nardell

at autopsies, and in surgery (Hutton et al. 1990). It is believed that once impacted onto surfaces, microorganisms in droplet nuclei are extremely difficult to re-aerosolize again as respirable particles (Ko et al. 1998). Dust generated by sweeping or shaking bedclothes, for example, may contain viable Mycobacterium tuberculosis $(M t b)$ organisms, but predominantly attached to relatively large, nonrespirable particles, impacting on the relatively resistant upper airways if inhaled rather than the lower respiratory tract. In a comprehensive investigation of shipboard transmission on a United States Navy vessel, no evidence was found of person-to-person spread by direct contact with respiratory droplets as occurs in influenza, for example, nor was there evidence of transmission through dust or fomites (Houk et al. 1968). Shared air fully accounted for the patterns of transmission seen.

Normally intracellular pathogens, $M t b$ bacilli are believed to die off during airborne transport, but at an uncertain rate, with measured half-lives in air ranging from $20 \mathrm{~min}$ to $6 \mathrm{~h}$ according to two different artificial aerosol experiments under optimal conditions of light, humidity, and temperature (Loudon et al. 1969a; Lever et al. 2000). The exact length of survival of viable and infectious naturally aerosolized organisms in air is unknown, and likely varies with ambient conditions, but it is clearly long enough for propagation of the infection under a variety of conditions around the world. On the other hand, in almost all cases, transmission is believed to require the simultaneous presence of both source cases and exposed persons, suggesting that risk decreases rapidly once the source case leaves. Dilution in room air and ventilation account for much of the rapid reduction in concentration, but die-off is another less well-defined factor. Barer has recently shown that a portion of tubercle bacilli recovered from human airways assume a spore-like phenotype by turning off unnecessary metabolic processes and storing fat (Garton et al. 2008). These "fat and lazy" organisms, he suggests, may be adapting to airborne transport, increasing their resistance to environmental stresses, and possibly adapted to ingestion and reversion to a replicating phenotype once inside the macrophage.

\section{Airborne Mycobacterium tuberculosis}

Once airborne, dilution, removal, or disinfection of indoor air are the main ways that the risk of airborne tubercle bacilli is reduced indoors (Nardell 1993b). It is not possible to culture naturally generated $M t b$ organisms from room air by air sampling because of low concentrations and overgrowth of more rapidly growing environmental bacteria and fungi. Although molecular methods have detected $M t b$ nucleic acid, advanced methods are required to estimate viability, and no molecular methods are able to determine infectivity, which requires a vulnerable host (Nardell 1999). However, good estimates of the concentration of infectious doses, what Wells called "infectious quanta," have been made epidemiologically in a few outbreak situations in which it was assumed that each infected person represented one infectious dose or quanta (Catanzaro 1982; Nardell et al. 1991). It has also been measured experimentally using large numbers of guinea pigs as quantitative air samplers (Riley et al. 1962). Guinea pigs are exquisitely susceptible to human $M t b$ and respond to tuberculin skin testing in a similar way (Smith et al. 1970). There is evidence to suggest that a single deeply inhaled infectious droplet nucleus can infect a guinea pig - and probably a vulnerable human as well (Riley 1957). During a 4-yr period, for example, Riley estimated an average concentration of infectious quanta of 1 in $11,000 \mathrm{cf}$ $\left(311 \mathrm{~m}^{3}\right)$ and also calculated that this extremely low average concentration was sufficient to explain the rates of transmission to student nurses in hospitals during the prechemotherapy era (Riley 1957; Riley et al. 1962). This same approach, using guinea pigs to quantify infectious quanta, has been used to measure the impact of such interventions as ultraviolet air disinfection, electrostatic precipitators, surgical masks on patients, and, most importantly, effective treatment as discussed below (Escombe et al. 2009; Dharmadhikari et al. 2012, 2014). 


\section{Dose and Risk of Infection}

Assuming complete susceptibility of exposed persons, the risk of acquiring a $\mathrm{TB}$ infection depends entirely on the chance of inhaling an infectious dose or quanta, and its progression to an established infection. As noted, for the guinea pig, the infectious dose has been estimated experimentally to be just one colony forming unit, that is, one quanta equals one droplet nucleus (Wells 1955). For humans with highly variable resistance, the exact infectious dose likely varies with microbial strain virulence and from person to person depending on host defenses, including general immunocompetence, innate immunity, adaptive immunity attributable to Bacillus Calmette-Guérin (BCG) immunization and prior exposure to $M t b$, leprosy, and related environmental mycobacteria. Contrary to common teaching, not all established TB infections persist (Nardell and Wallis 2006; Dharmadhikari et al. 2011). Because respirable particles cannot carry large numbers of organisms and are generally quite dilute in room air, the concept of dose is different from, for example, the dose of ingested food or waterborne organisms (Smith and Wiengeshaus 1989). Radiographs of children with primary TB indicate a random, mostly lower lung distribution of single foci of infection, not multiple foci-consistent with single implantations by chance caused by low average concentrations, as reported by Riley. It also seems likely that not every deeply inhaled droplet nucleus or "hit" containing TB organisms results in infection, or persistent infection (Nardell and Wallis 2006). This was the rationale for Wells' term "quanta" because the necessary number of inhaled droplet nuclei or hits necessary for one to result in a single infectious focus is not known (Wells 1955). Organisms can be nonviable, viable but not fully virulent, or by chance, encounter a particularly nonpermissive macrophage that halts progression. In natural human to guinea pig experiments similar to Riley's, we have described a range of outcomes following exposure, including transient tuberculin skin test responses that later revert without progression to disease, even following immunosuppression, and sometimes followed by a second or third tuberculin skin test response, suggesting reinfection (Dharmadhikari et al. 2011). Both humans and guinea pigs can show transient, self-limited immunological evidence of infection following exposure without progression and, ultimately, reversion of both immunological markers and risk (Friedman et al. 2006; Nardell and Wallis 2006). How often TB infections are transient is not known. Vaccination with BCG, the avirulent strain of Mycobacterium bovis, is the best-documented example of transient infection with reversion of tuberculin skin test over time in many, if not most, cases. Finally, with or without tuberculin reversion, exogenous reinfection commonly occurs with repeated exposure and has been postulated to be an essential pathogenic pathway to cavitary disease under endemic conditions (Smith and Wiengeshaus 1989).

Grzybowski et al. (1975) in British Colombia showed that children household contacts were more likely to get infected if the source case was both smear- and culture-positive rather than culture-positive only. Importantly, he also showed that contacts of smear-positive cases were more likely to progress to clinical disease given infection. This suggests a dose effect on progression from infection to disease. As noted above, this cannot be explained by larger numbers of organisms in individual droplet nuclei, but perhaps by multiple hits over time being more likely to overcome innate or adaptive immunity or impact in a vulnerable area of the lung. This is also consistent with many nonprogressive hits, or transient infections, before at least one that does progress (Smith and Wiengeshaus 1989).

Under steady-state conditions (however unlikely under real world conditions), the risk of infection $(C)$ is a function of several factors: (1) the number of infectious persons $(I)$ and source strength $(q)$-number of infectious quanta generated per hour or day; (2) the number of susceptible people breathing the same air $(S)$; (3) the breathing rate of exposed persons $(p) ;(4)$ the exposure time $(t)$; and (5) the ventilation rate of the room or rooms where exposure occurs $(Q)$. The relationship of these factors is captured by a mass balance relationship known 
E.A. Nardell

as the Wells-Riley equation, adapted from an epidemiological model by Edward Riley, Richard's brother, an engineer, to explain measles transmission in a school (Riley et al. 1978):

$$
C=S\left(1-e^{-I q p t / Q}\right)
$$

More recently, Rudnick and Milton (2003) have argued that human-generated indoor $\mathrm{CO}_{2}$ levels are a good surrogate of rebreathed air exposure, representing a more dynamic model of infection, accommodating the ever-changing non-steady-state conditions of real exposures.

\section{Source Factors}

There have been several outbreaks in which many of the essential transmission factors in the Wells-Riley equation were known or were estimated. In an office building TB exposure, in which building ventilation rates were known, one infectious source infected 27 of 67 susceptible occupants (40\%) over a 1 mo period, and the calculated $q$ was 13 quanta per hour. Other exposures have shown $q$ values as high as 250 quanta per hour compared with Riley's ward average figure of 1.25 quanta per hour (Riley et al. 1962; Catanzaro 1982; Nardell et al. 1991). This leads to one of the clearest facts about TB transmission-that patients vary greatly in infectiousness. It has been estimated that only one in three TB patients infects any close contacts (Fennelly et al. 2004; Fennelly 2007). Furthermore, it appears that a minority of infectious cases, so called "disseminators," accounts for much of observed transmission. This is true of other respiratory infections as well (Sultan et al. 1960).

Variability in infectiousness is believed to relate to the source patient, the strain, the host, and environmental factors, but they are difficult to separate. The same source patient and strain will infect more contacts in a crowded, poorly ventilated environment with highly susceptible hosts. Frequency of cough, viscosity of respiratory secretions, presence of lung cavities or laryngeal disease, and duration of exposure are important variables (Loudon and Spohn 1969). Among potential interventions to reduce transmission, however, nothing is as rapidly and completely effective than treatment with the appropriate drug regimen, as will be discussed below (Rouillon et al. 1976).

\section{ADMINISTRATIVE APPROACHES TO TB TRANSMISSION CONTROL}

\section{Known or Suspected versus Unsuspected Cases}

Most interventions to prevent transmission focus on the known or suspected case, often on effective treatment, but there is ample evidence that unsuspected, untreated cases account for much more transmission (Jensen et al. 2005). Under high-burden conditions, TB is commonly missed in persons presenting with unrelated conditions (Willingham et al. 2001; Bates et al. 2012, 2013). Under low-burden conditions, the diagnosis is less likely to be considered even with classical symptoms. Studies in Peru and Africa have shown the prevalence of unsuspected $\mathrm{TB}$ in general medical settings, including smear-positive, drug-resistant cases (Willingham et al. 2001; Bates et al. 2012).

\section{Interventions to Reduce Transmission}

Breathing shared air is required for transmission, and separation or isolation of suspected infectious source is usually the first and most immediately effective administrative and environmental approach. However, much household transmission is likely to have occurred before symptoms lead patients to a diagnosis and treatment, at which point transmission normally stops abruptly, as discussed below. Contact tracing and active case finding in the community can find cases earlier but the latter, unless targeted to high-incidence populations, may not be cost-effective (Gilpin and Hammond 1987; Puisis et al. 1996; Zachariah et al. 2003; Gounder et al. 2011; Hoek et al. 2011; Lorent et al. 2014). Active case finding leading to rapid diagnosis and effective treatment may be highly effective in some congregate settings in identifying otherwise unsuspected cases, but it requires resources and a highly organized in- 
frastructure and, ideally, the on-site availability of rapid molecular diagnostics tests. In theory, if all entrants to a general medical ward are screened for unexplained chronic cough, and all otherwise unsuspected pulmonary cases diagnosed and effectively treated, there would be few, if any, sources of transmission. Because of the power of drug susceptibility test (DST)directed treatment to stop transmission, it will be discussed first, followed by environmental interventions and respiratory protection, which play secondary roles-unless administrative control is incompletely successful.

\section{Impact of Treatment on Transmission}

That effective treatment rapidly stops transmission was suspected soon after chemotherapy was introduced (Crofton 1962). Confidence that patients on effective treatment become quickly noninfectious was the basis for shifting to completely ambulatory treatment. In a review article on the impact of treatment on transmission among household contacts, Roullion and colleagues concluded that infectiousness ended well before sputum smear or culture conversion, "probably in less than two weeks" (Rouillon et al. 1976). Although the "two-week rule" has guided practice before the resurgence of drug-resistant $\mathrm{TB}$, there is more direct evidence of an even faster impact of effective treatment on transmission. In his initial 2-yr human to guinea pig study in the late 1950s, Riley et al. (1995) found that transmission occurred primarily (21 of 22 infections) from chronic patients, on treatment, but resistant to one or more of the three available antibiotics at the time. In the second 2-yr study, treatment was delayed for one group of patients, but it started immediately on admission for another group. Among patients with drug-susceptible TB, there was an almost immediate $98 \%$ reduction in transmission in the treated group, adjusting for time on the ward (Riley et al. 1962). Therefore, the effect of chemotherapy on transmission appears to have been rapid, well before the 2-wk estimate based on epidemiological studies. For drug-resistant cases, the few remaining drugs also seemed to be promptly ef- fective, but the numbers of such cases were too few, Riley felt, to be sure.

Using a similar human to guinea pig model in South Africa, preliminary observations suggest that even multidrug-resistant (MDR) TB appears to respond quickly to appropriate treatment (Dharmadhikari et al. 2014). Considering the three drugs available in Riley's studies, isoniazid (INH), streptomycin, and para-aminosalicylic acid (PAS), INH was most likely responsible owing to its early bactericidal activity. For MDR-TB, in which both INH and rifamycin are ineffective, we speculate that fluoroquinolones may be responsible for the rapid effect of treatment on transmission. Loudon speculated that it could be the high residual concentration of drug in droplet nuclei as they evaporate that accounts for the rapid effect on transmission, but he was unable to produce confirmatory evidence (Loudon et al. 1969b). The observed discordance on transmission by patients on effective treatment, with positive sputum smears and culture, in both household contact and guinea pig transmission studies, may reflect aerosolization stress and high local drug concentrations, but this discordance could also represent immediate stress effects of certain drugs on specific $M t b$ metabolic functions that are necessary for successful implantation in an immunocompetant host but not for growth of sputum samples in supportive culture media. Further basic research on the rapid effects of treatment is warranted.

\section{FAST: An Intensified, Refocused Approach to TB Transmission}

The advent and wide use of new rapid molecular diagnostics together with a renewed appreciation of the rapid impact of treatment on transmission has led us to a reformulated approach to $\mathrm{TB}$ infection control that we call FAST: find cases actively, separate safely, and treat effectively based on rapid DST (Nardell and Dharmadhikari 2010).

To reiterate, the FAST approach is based on four underlying principles: (1) That TB is spread in institutions predominantly by coughing patients with unsuspected TB or unsuspect- 
ed drug resistance; (2) that most potentially infectious patients can be identified by cough surveillance; (3) that coughing TB patients most likely to be infectious can be diagnosed by rapid molecular sputum tests, including drug resistance (GeneXpert ${ }^{\circledR}$ MTB/RIF); and (4) that by dramatically reducing institutional exposure duration through effective treatment, transmission among patients and to health-care workers will be reduced proportionately (Boehme et al. 2010). Although these are solid principles, like most transmission control interventions, their efficacy in preventing transmission has yet to be proven, and there are many practical barriers to implementation.

In many high-burden settings, health-care workers are already overstretched. Who will do cough surveillance? Who will assure that sputum is promptly collected, delivered to the lab, results obtained, and effective treatment started? If these activities are as critical in stopping transmission as we contend, they cannot be assigned to volunteers or simply added to already full workloads. Where, then, are the sustainable funding sources for the additional human resources, GeneXpert MTB/RIF machines, and laboratory supplies? If the benefits in terms of secondary cases averted were obvious, the costs of prevention through rapid diagnosis and effective treatment might be easily justified, but they rarely are clear. On the other hand, diagnosing and treating active TB is a fundamental public health and personal health imperative-it must be performed sooner or later. The argument here is that the public health and personal health benefits of diagnosing and treating sooner through active surveillance, rapid diagnostic testing, and effective treatment will far outweigh the added costs, especially for MDR TB in which the costs, both human and financial, are staggering for each additional case transmitted (Fitzpatrick and Floyd 2012). Demonstrations of reduced transmission in clinical settings and formal cost-benefit analyses are needed.

Unlike hand washing to prevent dropletspread infection, effective FAST implementation is fundamentally not an educational campaign for employees, although understanding its rationale is important for achieving its ambitious goals. FAST implementation requires an institutional investment in resources and specific personnel to introduce new policies and procedures (and streamline old ones) to achieve the goal of reduced exposure time. Although it has proven difficult to measure the impact of any TB infection control interventions in terms of reduced transmission, the process indicators entailed (time from admission to cough detection, time from cough detection to sputum submission, Xpert turnaround time, and time from admission to effective therapy) are measureable and logically closely tied to exposure duration. Performance goals for these process indicators should be set, and achieving those measurable goals should be considered by funding agencies as primary proof of impact. Improvements and slippage in performance process indicators can be tracked over time.

\section{AMBULATORY VERSUS INPATIENT TB TREATMENT}

The site of treatment, hospital versus clinic or home, has transmission control implications. As mentioned, when numerous household contact studies in the 1960s and 1970s suggested little additional risk of transmission in the home, ambulatory treatment became the norm around the world for uncomplicated, drug susceptible cases (Andrews et al. 1960). Many programs also treat MDR TB in the community or in clinics, but other programs continue to treat in hospital, at least for the period while daily injections are given. Community-based programs have been shown to have outcomes as good as or better than hospital-based programs, and the cost is much less in the community, and it is usually easier on patients and families (Fitzpatrick and Floyd 2012). Again, our human to guinea pig transmission studies suggest that MDR treatment is also rapidly effective in preventing transmission, so the risk in the community or hospital should not be an issue, although more vulnerable patients are concentrated in hospitals. Community-based MDR programs do require a developed community infrastructure. Experienced groups have pub- 
lished guidelines for community-based MDR programs (Mitnick et al. 2003).

\section{ENVIRONMENTAL APPROACHES TO TB TRANSMISSION CONTROL}

In the traditional industrial hygiene hierarchical approach to safety in the workplace, environmental controls come into play when administrative source controls cannot provide adequate protection, and respiratory protection is used when both administrative and environmental controls are inadequate. Common TB infection control practice has been to use all three approaches, implicitly indicating that none are fully effective (Jensen et al. 2005).

\section{Crowding, Building Design, and Usage}

Environmental control begins with the building. Occupancy rate (crowding) and building use are fundamental factors in $\mathrm{TB}$ transmission and control. Consider a hypothetical large room with 100 occupants with a $2 \%$ risk of TB. Simplistically, there would be two active cases and 98 other occupants exposed to them. Divide those same 100 occupants into 10 rooms of 10 occupants each and suddenly only two rooms (and possibly one) have a TB case and only eight to 18 others are exposed, an $82 \%-92 \%$ risk reduction simply by dividing up occupants into smaller clusters. Although hypothetical, the principle is broadly applicable, for example, to the design and use of hospital or clinic waiting rooms.

Space does not allow an exhaustive discussion of hospital design and engineering for airborne infection control. Courses are available for architects, engineers, and administrators to learn the principles. Application of these principles has resulted in award-winning designs around the world, but actual assessment of building designs from an airborne infection perspective remains elusive. Ventilation and space usage can be documented at specific rooms and times of day, but exposure is often in multiple rooms and 24/7. A more meaningful assessment of buildings must consider the degree to which occupants share air throughout the day and in different seasons (Rudnick and Milton 2003).

\section{Ventilation}

Buildings must be ventilated, defined for contagion purposes as replacing a portion of room/ building air with a percentage of outside air, presumed free of airborne pathogens. In many high-burden, resource-limited settings in mild climates, natural ventilation is the common and essential means of air disinfection. In other less hospitable climates, especially in resource-rich settings, mechanical ventilation of hospitals and clinics may be the norm, although many (World Health Organization 2009) older buildings still depend on radiator heat and operable windows. Most ventilation systems are designed for comfort, not airborne infection control (Nardell et al. 1991). The difference is that levels of ventilation adequate for odor control are generally not adequate for infection control, depending on source strength and duration of exposure. Recommendations exist for both natural and mechanical ventilation for airborne infection control, but implementation and maintenance are often challenging (Jensen et al. 2005; Escombe et al. 2007; Atkinson et al. 2009).

Natural ventilation depends entirely on pressure differences created by wind or on temperature differences that cause warm air to rise and replacement air to enter (Atkinson et al. 2009). Buildings designed for natural ventilation need to have adequate openings and be properly sited for wind or use other specialized features such as wind catchers, solar heating stacks, or rooftop whirlybird ventilators. Simple rules of thumb, such as window open area being $10 \%$ or $20 \%$ of floor area can be highly misleading. The window area needed is entirely dependent on each situation. In windy locations, for example, moderate openings with cross-ventilation may be adequate, whereas in poorly sited buildings without cross-ventilation, even large openings may be inadequate. Ventilation estimates using $\mathrm{CO}_{2}$ decay curves have been reported for hospitals in Peru at 60 or more air changes per hour $(\mathrm{ACH})$, but ventilation experts have challenged 
the accuracy of $\mathrm{CO}_{2}$ decay measurements, often taken at one location, at one time, and in one season (Escombe et al. 2007). Nonetheless, such measurements are usually good enough to be able to say with certainty that ventilation is adequate or not at that moment and in that location. Renovation of older buildings for new uses presents greater challenges than new construction from an airborne infection perspective. The necessary climatic conditions, building site, and structural features may not be present for effective use of this modality.

Where natural ventilation is the main mode, provisions need to be made to assure that windows and other openings stay open day and night and in all seasons. Occupants often close windows for security, to keep out vermin, or because of cold, and each of these concerns need to be addressed if natural ventilation is to remain effective.

\section{Mechanical Ventilation}

Mechanical and hybrid (or mixed-mode) mechanical-natural systems are less dependent on climatic conditions, but they are heavily dependent on the initial design, subsequent renovations, and, importantly, maintenance. For airborne infection control, six to $12 \mathrm{ACH}$ outside air are commonly recommended (Jensen et al. 2005; World Health Organization 2009). In cold climates, and in warm climates in which cooling is provided, this can be extremely expensive in terms of energy use. Even six to 12 $\mathrm{ACH}$ can prove inadequate if the source strength is great or exposure prolonged. As a general rule, under well-mixed conditions, doubling the outdoor ventilation rate reduces the risk of infection by half. Doubling ventilation again reduces risk by half again, and so on for each doubling. Clearly, there are practical limits to increasing ventilation rates because of system capacity, comfort, cost, and noise (Nardell et al. 1991). Although not true outside air ventilation, two additional interventions can provide the equivalent of air changes per hour $(\mathrm{EqACH})$ from an infection control perspective-upper-room ultraviolet germicidal irradiation (UVGI) and room air cleaners.

\section{Upper Room UVGI}

Air disinfection by UVGI is the least well-understood intervention by engineers and architects, but also among the most well-studied, effective, and cost effective of environmental interventions (First et al. 2007; Rudnick and First 2007). Special 254-nm wavelength germicidal lamps in wall or suspended fixtures provide an irradiated zone of air in the upper room, above the heads of occupants. Good air mixing, best assured by low-velocity ceiling fans, brings contaminated air to the upper room and returns disinfected air to the lower room. Because the entire upper room area is available as an air disinfection chamber, room air turnover rates through the upper room can be high, approaching $60 \mathrm{ACH}$ in a recent study, using commercially available inexpensive ceiling fans. Both room testing and modeling suggest that neither fan velocity nor direction are critical factors, although some fan experts favor downward direction in rooms with high ceilings to avoid lower room stagnation (Escombe et al. 2009; Zhu et al. 2013, 2014). Low vertical air velocity results in longer but fewer passages of particles through the irradiated zone, whereas with higher vertical air velocities, particle exposure per pass is shorter, but passages are more frequent, with similar net exposure.

The fundamental factors determining the efficacy of upper-room UVGI are (1) well-designed wall or center-mounted fixtures generating a prescribed UV output to the upper room (usually louvered to produce low levels to the occupied space); (2) optimal ray length, that is, locating fixtures on walls to achieve maximum use of available germicidal energy; and (3) good vertical air mixing, as noted above. Based on a well-characterized study of UVGI efficacy in a South African TB hospital, new room dosing guidelines based on fixture output have been published. The basic recommendation is to provide $\sim 20 \mathrm{~mW}$ total fixture output per cubic meter of room volume, with the additional requirement that wall fixtures be arranged for maximum average ray length. This dosing recommendation requires that the total fixture UV output of commercial fixtures be provided by manufacturers, which is currently not done. 
Upper-room UVGI has a good safety record, with most eye or skin overexposure resulting from poor fixture design or placement (Nardell 1993b; Rudnick 2001; Nardell et al. 2008, 2013). Guidelines for evaluating UV fixture safety and for maintenance are available (First et al. 1999a,b). The threshold limit value (TLV) for UVGI is $6 \mathrm{~mJ} / \mathrm{cm}^{2}$ over any $8 \mathrm{~h}$ exposure period (ACGIH 1999). Occupant movement within rooms with UVGI greatly reduces exposure, and no single irradiance value should be used as a safety threshold. Depending on how the space is used, maximum eye level irradiance levels of 0.4 to $0.6 \mu \mathrm{W} / \mathrm{cm}^{2}$ are routinely well-tolerated because eye and skin exposure is well within the TLV (First et al. 2005). The main maintenance requirement is to turn off and clean lamps with $70 \%$ alcohol periodically, the frequency based on the cleanliness of the environment, and the replacement of lamps, most cost-effectively when measured output drops by $30 \%$ from commissioning values when measured in a standard way.

Room air cleaners are rarely recommended, despite claims of sales personnel that they are the answer to TB infection control (Nardell 1993a). Their problem is that, although either HEPA (high-efficiency particulate air) filters or UVGI inside the box can readily remove or inactivate infectious organisms, rarely can these units provide effective clean air delivery (CADR) adequate for TB infection control (Miller-Leiden et al. 1996). Many units simply provide too few equivalent air changes per hour, and almost all are subject to "short circuiting" of air, reentrapment of air that just exited the unit. Faced with optimistic claims, hospital administrators often jump at the opportunity to solve TB infection control by plugging in a device. Considering short circuiting, many units provide less than 1 equivalent $\mathrm{ACH}$, and rarely can they approach the air disinfection achievable by optimal natural ventilation or upper-room UVGI.

\section{RESPIRATORY PROTECTION}

Respirators are last in the hierarchy of interventions because they cannot be worn constantly and are likely not to be used for unsuspected, untreated TB patients, the greatest threat for transmission (NEHW Health Watch 1992; Centers for Disease Control and Prevention 1996; Coffey et al. 1998, 2004; Fennelly and Nardell 1998; Jensen et al. 2005; World Health Organization 2009). By convention, respirators refer to devices that cover the nose and mouth for the purpose of protecting the wearer, whereas masks, such as surgical masks, are intended to protect the environment, such as the surgical field. Respirators have several features to ensure a tight fit to prevent face seal leak, the main reason for incomplete protection. They normally have a pliable nose clip to allow a close fit around the nose and two elastic straps to assure adherence to the face. Respirators used for TB infection control are usually the disposable type (N95 or equivalent) with a filtering face piece, although reusable industrial elastomeric respirators can be used with the appropriate filter cartridges (Centers for Disease Control and Prevention 1996). All respirators require fit testing on the wearer at least once to assure that the anticipated protection factor is obtained. Normally, institutions have several sizes and styles of respirators available because no one size or style fits every face. More details on respirator use and fit testing are available on line (http:// www.cdc.gov/niosh/npptl/topics/respirators/ disp_part/) (Coffey et al. 2002). Surgical masks are sometimes recommended for patients who cannot cover their coughs or sneezes, they are less expensive in one study; however, they provided only a $53 \%$ reduction in infectious cough aerosol (Dharmadhikari et al. 2012). This is not insignificant, the equivalent reduction to doubling room ventilation, but it does not assure that transmission will not occur. Respirators are not normally used for infectious patients because only a barrier to stop respiratory droplets is required-not air filtration.

\section{Health-Care Worker Surveillance}

Periodic testing of health-care workers for latent TB infection (LTBI) or active disease is commonly performed in some countries, but not others. High rates of community-acquired infection and policies that do not include treat- 
E.A. Nardell

ment for LTBI are among the reasons that many workers are not tested. Radiological screening of asymptomatic workers is generally not cost effective (Menzies et al. 2007; Cummings et al. 2009; de Perio et al. 2009). Worker education about TB and its symptoms can reduce the stigma of the disease, which sometimes is a barrier to workers seeking care. In low-burden settings, testing for LTBI by tuberculin skin testing or interferon- $\gamma$ release assays is difficult because of test performance issues. In high-burden settings, it can also be difficult to interpret test results, but skin testing has been used effectively in medical and nursing students as a good indicator of institutional transmission (Silva et al. 2000). Unfortunately, although effective, treatment of latent TB infection is often incomplete because of nonadherence (MMWR Recomm Rep 2000).

\section{REFERENCES}

ACGIH. 1999. Documentation of the threshold limit values and biological exposure indices. American Conference of Governmental Industrial Hygienists, Cincinnati.

Andrews RH, Devadatta S, Fox W, Radhakrishna S, Ramakrishnan CV, Velu S. 1960. Prevalence of tuberculosis among close family contacts of tuberculous patients in South India, and influence of segregation of the patient on early attack rate. Bull World Health Organ 23: 463-510.

Atkinson J, Chartier Y, Pessoa-Silva CL, Jensen P, Li Y, Seto WH. 2009. Natural Ventilation for Infection Control in Health Care Settings. WHO, Geneva.

Bacaër N, Ouifki R, Pretorius C, Wood R, Williams B. 2008. Modeling the joint epidemics of TB and HIV in a South African township. J Math Biol 57: 557-593.

Bates M, O’Grady J, Mwaba P, Chilukutu L, Mzyece J, Cheelo B, Chilufya M, Mukonda L, Mumba M, Tembo J, et al. 2012. Evaluation of the burden of unsuspected pulmonary tuberculosis and co-morbidity with non-communicable diseases in sputum producing adult inpatients. PloS ONE 7: e40774.

Bates M, Ahmed Y, Chilukutu L, Tembo J, Cheelo B, Sinyangwe S, Kapata N, Maeurer M, O’Grady J, Mwaba P, et al. 2013. Use of the Xpert ${ }^{\circledR}$ MTB/RIF assay for diagnosing pulmonary tuberculosis comorbidity and multidrug-resistant TB in obstetrics and gynaecology inpatient wards at the University Teaching Hospital, Lusaka, Zambia. Trop Med Int Health 18: 1134-1140.

Boehme CC, Nabeta P, Hillemann D, Nicol MP, Shenai S, Krapp F, Allen J, Tahirli R, Blakemore R, Rustomjee R, et al. 2010. Rapid molecular detection of tuberculosis and rifampin resistance. $N$ Engl J Med 363: 1005-1015.

Catanzaro A. 1982. Nosocomial tuberculosis. Am Rev Respir Dis 125: 559-562.
Centers for Disease Control and Prevention. 1996. NIOSH Guide to the selection and use of particulate respirators certified under 42 CFR 84. [DHHS (NIOSH) Pub No. 96101]. National Institutes for Occupational Safety and Health, HHS, CDC. Cincinnati.

Coffey CC, Campbell DL, Myers WR, Zhuang Z. 1998. Comparison of six respirator fit-test methods with an actual measurement of exposure in a simulated health care environment: Part II-Method comparison testing. Am Ind Hyg Assoc J 59: 862-870.

Coffey CC, Lawrence RB, Zhuang Z, Campbell DL, Jensen PA, Myers WR. 2002. Comparison of five methods for fittesting N95 filtering-facepiece respirators. Appl Occup Environ Hyg 17: 723-730.

Coffey CC, Lawrence RB, Campbell DL, Zhuang Z, Calvert CA, Jensen PA. 2004. Fitting characteristics of eighteen N95 filtering-facepiece respirators. J Occup Environ Hyg 1: $262-271$.

Crofton J. 1962. The contribution of treatment to the prevention of tuberculosis. Bull Int Union Tuberc 32: 643653.

Cummings KJ, Smith TS, Shogren ES, Khakoo R, Nanda S, Bunner L, Smithmyer A, Soccorsi D, Kashon ML, Mazurek GH, et al. 2009. Prospective comparison of tuberculin skin test and QuantiFERON-TB Gold In-Tube assay for the detection of latent tuberculosis infection among healthcare workers in a low-incidence setting. Infect Control Hosp Epidemiol 30: 1123-1126.

de Perio MA, Tsevat J, Roselle GA, Kralovic SM, Eckman MH. 2009. Cost-effectiveness of interferon $\gamma$ release assays vs tuberculin skin tests in health care workers. Arch Intern Med 169: 179-187.

Dharmadhikari AS, Basaraba RJ, Van Der Walt ML, Weyer K, Mphahlele M, Venter K, Jensen PA, First MW, Parsons S, McMurray DN, et al. 2011. Natural infection of guinea pigs exposed to patients with highly drug-resistant tuberculosis. Tuberculosis 91: 329-338.

Dharmadhikari AS, Mphahlele M, Stoltz A, Venter K, Mathebula R, Masotla T, Lubbe W, Pagano M, First M, Jensen PA, et al. 2012. Surgical face masks worn by patients with multidrug-resistant tuberculosis: Impact on infectivity of air on a hospital ward. Am J Respir Crit Care Med 185: 1104-1109.

Dharmadhikari AS, Mphahlele M, Venter K, Stoltz A, Mathebula R, Masotla T, van der Walt M, Pagano M, Jensen P, Nardell E. 2014. Rapid impact of effective treatment on transmission of multidrug-resistant tuberculosis. Int J Tuberc Lung Dis 18: 1019-1025.

Escombe AR, Oeser CC, Gilman RH, Navincopa M, Ticona E, Pan W, Martínez C, Chacaltana J, Rodríguez R, Moore DA, et al. 2007. Natural ventilation for the prevention of airborne contagion. PLoS Med 4: e68.

Escombe AR, Moore DA, Gilman RH, Navincopa M, Ticona E, Mitchell B, Noakes C, Martínez C, Sheen P, Ramirez R, et al. 2009. Upper-room ultraviolet light and negative air ionization to prevent tuberculosis transmission. PLoS Med 6: e43.

Fennelly KP. 2007. Variability of airborne transmission of Mycobacterium tuberculosis: Implications for control of tuberculosis in the HIV era. Clin Infect Dis 44: 13581360. 
Fennelly K, Nardell E. 1998. The relative efficacy of respirators and room ventilation in preventing occupational tuberculosis. Inf Control Hosp Epidemiol 19: 754-759.

Fennelly KP, Martyny JW, Fulton KE, Orme IM, Cave IM, Heifets LB. 2004. Cough-generated aerosols of Mycobacterium tuberculosis: A new method to study infectiousness. Am J Respir Crit Care Med 169: 604-609.

First M, Nardell EA, Chaisson W, Riley R. 1999a. Guidelines for the application of upper-room ultraviolet germicidal irradiation for preventing transmission of airborne contagion-Part II: Design and operations guidance. $\mathrm{ASH}-$ RAE Trans 105: 877-887.

First M, Nardell EA, Chaisson W, Riley R. 1999b. Guidelines for the application of upper-room ultraviolet germicidal irradiation for preventing transmission of airborne contagion-Part I: Basic principles. ASHRAE Trans 105: 869-876.

First MW, Weker RA, Yasui S, Nardell EA. 2005. Monitoring human exposures to upper-room germicidal ultraviolet irradiation. J Occup Environ Hyg 2: 285-292.

First M, Rudnick SN, Banahan KF, Vincent RL, Brickner PW. 2007. Fundamental factors affecting upper-room ultraviolet germicidal irradiation-Part I. Experimental. J Occup Environ Hyg 4: 321-331.

Fitzpatrick C, Floyd K. 2012. A systematic review of the cost and cost effectiveness of treatment for multidrug-resistant tuberculosis. Pharmacoeconomics 30: 63-80.

Friedman LN, Nash ER, Bryant J, Henry S, Shi J, D’Amato J, Khaled GH, Russi MB, O'Connor PG, Edberg SC, et al. 2006. High rate of negative results of tuberculin and QuantiFERON tests among individuals with a history of positive skin test results. Infect Control Hosp Epidemiol 27: $436-441$.

Garton NJ, Waddell SJ, Sherratt AL, Lee SM, Smith RJ, Senner C, Hinds J, Rajakumar K, Adegbola RA, Besra GS, et al. 2008. Cytological and transcript analyses reveal fat and lazy persister-like bacilli in tuberculous sputum. PLoS Med 5: e75.

Gilpin TP, Hammond M. 1987. Active case-finding-For the whole community or for tuberculosis contacts only? $S$ Afr Med J 72: 260-262.

Gounder CR, Wada NI, Kensler C, Violari A, McIntyre J, Chaisson RE, Martinson NA. 2011. Active tuberculosis case-finding among pregnant women presenting to antenatal clinics in Soweto, South Africa. J Acquir Immune Defic Syndr 57: e77-e84

Grzybowski S, Barnett GD, Styblo K. 1975. Contacts of cases of active pulmonary tuberculosis. Bull Int Union Tuberc 50: 90-106.

Hoek KG, Van Rie A, van Helden PD, Warren RM, Victor TC. 2011. Detecting drug-resistant tuberculosis: The importance of rapid testing. Mol Diagn Ther 15: 189-194.

Houk VH, Kent DC, Baker JH, Sorensen K, Hanzel GD. 1968. The Byrd study. In-depth analysis of a micro-outbreak of tuberculosis in a closed environment. Arch Environ Health 16: 4-6.

Hutton MD, Stead WW, Cauthen GM, Bloch AB, Ewing WM. 1990. Nosocomial transmission of tuberculosis associated with a draining abscess. J Infect Dis 161: 286295.
Jensen PA, Lambert LA, Iademarco MF, Ridzon R. 2005. Guidelines for preventing the transmission of Mycobacterium tuberculosis in health-care settings. MMWR Recomm Rep 54: 1-141.

Johnstone-Robertson S, Lawn SD, Welte A, Bekker LG, Wood R. 2011a. Tuberculosis in a South African prison-A transmission modelling analysis. S Afr Med J 101: 809-813.

Johnstone-Robertson SP, Mark D, Morrow C, Middelkoop K, Chiswell M, Aquino LD, Bekker LG, Wood R. 2011b. Social mixing patterns within a South African township community: Implications for respiratory disease transmission and control. Am J Epidemiol 174: 1246-1255.

Joshi R, Reingold AL, Menzies D, Pai M. 2006. Tuberculosis among health-care workers in low- and middle-income countries: A systematic review. PLoS Med 3: e494.

Ko G, Burge HA, Muilenberg M, Rudnick S, First M. 1998. Survival of mycobacteria on HEPA filter material. Appl Biosaf 3: 65-78.

Lever MS, Williams A, Bennett AM. 2000. Survival of mycobacterial species in aerosols generated from artificial saliva. Lett Appl Microbiol 31: 238-241.

Lorent N, Choun K, Thai S, Kim T, Huy S, Pe R, van Griensven J, Buyze J, Colebunders R, Rigouts L, et al. 2014. Community-based active tuberculosis case finding in poor urban settlements of Phnom Penh, Cambodia: A feasible and effective strategy. PloS ONE 9: e92754.

Loudon RG, Spohn SK. 1969. Cough frequency and infectivity in patients with pulmonary tuberculosis. Am Rev Respir Dis 99: 109-111.

Loudon RG, Bumgarner LR, Lacy J, Coffman GK. 1969a. Aerial transmission of mycobacteria. Am Rev Respir Dis 100: $165-171$.

Loudon RG, Bumgarner LR, Coffman GK. 1969b. Isoniazid and the survival of tubercle bacilli in airborne droplet nuclei. Am Rev Respir Dis 100: 172-176.

Menzies D, Joshi R, Pai M. 2007. Risk of tuberculosis infection and disease associated with work in health care settings. Int J Tuberc Lung Dis 11: 593-605.

Middelkoop K, Bekker LG, Myer L, Dawson R, Wood R. 2008. Rates of tuberculosis transmission to children and adolescents in a community with a high prevalence of HIV infection among adults. Clin Infect Dis 47: 349355.

Miller-Leiden S, Lobascio C, Nazaroff WW, Macher JM. 1996. Effectiveness of in-room air filtration and dilution ventilation for tuberculosis infection control. J Air Waste Manag Assoc 46: 869-882.

Mitnick C, Bayona J, Palacios E, Shin S, Furin J, Alcántara F, Sánchez E, Sarria M, Becerra M, Fawzi MC, et al. 2003. Community-based therapy for multidrug-resistant tuberculosis in Lima, Peru. N Engl J Med 348: 119-128.

MMWR Recomm Rep. 2000. Targeted tuberculin testing and treatment of latent tuberculosis infection. MMWR Recomm Rep 49: 1-51.

Nardell E. 1993a. Fans, filters, or rays? Pros and cons of the current envirnonmental tuberculosis control technologies. Infect Control Hosp Epidemiol 14: 681-685.

Nardell EA. 1993b. Environmental control of tuberculosis. Med Clin North Am 77: 1315-1334. 
E.A. Nardell

Nardell EA. 1999. Air sampling for tuberculosis—-Homage to the lowly guinea pig. Chest 116: 1143-1145.

Nardell EA, Wallis RS. 2006. Here today-Gone tomorrow: The case for transient acute tuberculosis infection. Am J Respir Crit Care Med 174: 734-735.

Nardell E, Dharmadhikari A. 2010. Turning off the spigot: Reducing drug-resistant tuberculosis transmission in resource-limited settings. Int J Tuberc Lung Dis 14: 12331243.

Nardell EA, Keegan J, Cheney SA, Etkind SC. 1991. Airborne infection. Theoretical limits of protection achievable by building ventilation. Am Rev Respir Dis 144: 302-306.

Nardell EA, Bucher SJ, Brickner PW, Wang C, Vincent RL, Becan-McBride K, James MA, Michael M, Wright JD. 2008. Safety of upper-room ultraviolet germicidal air disinfection for room occupants: Results from the Tuberculosis Ultraviolet Shelter Study. Public Health Rep 123: $52-60$.

Nardell E, Vincent R, Sliney DH. 2013. Upper-room ultraviolet germicidal irradiation (UVGI) for air disinfection: A symposium in print. Photochem Photobiol 89: 764769.

NEHW Health Watch. 1992. Particulate respirators and tuberculosis transmission. NEHW Health Watch 12: 8-9.

Ordway D, Harton M, Henao-Tamayo M, Montoya R, Orme IM, Gonzalez-Juarrero M. 2006. Enhanced macrophage activity in granulomatous lesions of immune mice challenged with Mycobacterium tuberculosis. J Immunol 176: 4931-4939.

Orme IM. 2014. A new unifying theory of the pathogenesis of tuberculosis. Tuberculosis 94: 8-14.

Puisis M, Feinglass J, Lidow E, Mansour M. 1996. Radiographic screening for tuberculosis in a large urban county jail. Public Health Rep 111: 330-334.

Riley R. 1957. Aerial dissemination of pulmonary tuberculosis-The Burns Amberson lecture. Am Rev Tuberc Pulmon Dis 76: 931-941.

Riley RL. 1974. Airborne infection. Am J Med 57: 466-475.

Riley RL, Mills CC, O'Grady F, Sultan LU, Wittstadt F, Shivpuri DN. 1962. Infectiousness of air from a tuberculosis ward. Ultraviolet irradiation of infected air: Comparative infectiousness of different patients. Am Rev Respir Dis 85: 511-525.

Riley E, Murphy G, Riley R. 1978. Airborne spread of measles in a suburban elementary school. Am J Epidemiol 107: 421-432.

Riley RL, Mills CC, Nyka W, Weinstock N, Storey PB, Sultan LU, Riley MC, Wells WF. 1995. Aerial dissemination of pulmonary tuberculosis: A two-year study of contagion in a tuberculosis ward: 1959. Am J Epidemiol 142: 3-14.
Rouillon A, Perdrizet S, Parrot R. 1976. Transmission of tubercle bacilli: The effects of chemotherapy. Tubercle 57: 275-299.

Rudnick SN. 2001. Predicting the ultraviolet radiation distribution in a room with multilouvered germicidal fixtures. AIHAJ 62: 434-445.

Rudnick SN, First MW. 2007. Fundamental factors affecting upper-room ultraviolet germicidal irradiation-Part II. Predicting effectiveness. JOccup Environ Hyg 4: 352-362.

Rudnick SN, Milton DK. 2003. Risk of indoor airborne infection transmission estimated from carbon dioxide concentration. Indoor Air 13: 237-245.

Silva VM, Cunha AJ, Oliveira JR, Figueira MM, Nunes ZB, DeRiemer K, Kritski AL. 2000. Medical students at risk of nosocomial transmission of Mycobacterium tuberculosis. Int J Tuberc Lung Dis 4: 420-426.

Smith D, Wiengeshaus E. 1989. What animal models can teach us about the pathogenesis of tuberculosis in humans. Rev Infect Dis 11: S385-S393.

Smith DW, McMurray DN, Wiegeshaus EH, Grover AA, Harding GE. 1970. Host-parasite relationships in experimental airborne tuberculosis. IV. Early events in the course of infection in vaccinated and nonvaccinated guinea pigs. Am Rev Respir Dis 102: 937-949.

Sultan L, Myka W, Mills C, O’Grady F, Wells W, Riley RL. 1960. Tuberculosis disseminators-A study of variability of aerial infectivity of tuberculosis patients. Am Rev Respir Dis 82: 358-369.

Wells WF. 1955. Airborne Contagion and Air Hygiene. Harvard University Press: Cambridge, MA.

Willingham FF, Schmitz TL, Contreras M, Kalangi SE, Vivar AM, Caviedes L, Schiantarelli E, Neumann PM, Bern C, Gilman RH, et al. 2001. Hospital control and multidrugresistant pulmonary tuberculosis in female patients, Lima, Peru. Emerg Infect Dis 7: 123-127.

World Health Organization. 2009. WHO Policy on TB Infection Control in Health-Care Facilities, Congregate Settings and Households. WHO, Geneva.

Zachariah R, Spielmann MP, Harries AD, Gormani P, Graham SM, Bakali E, Humblet P. 2003. Passive versus active tuberculosis case finding and isoniazid preventive therapy among household contacts in a rural district of Malawi. Int J Tuberc Lung Dis 7: 1033-1039.

Zhu S, Srebric J, Rudnick SN, Vincent RL, Nardell EA. 2013. Numerical investigation of upper-room UVGI disinfection efficacy in an environmental chamber with a ceiling fan. Photochem Photobiol 89: 782-791.

Zhu S, Srebric J, Rudnick SN, Vincent RL, Nardell EA. 2014. Numerical modeling of indoor environment with a ceiling fan and an upper-room ultraviolet germicidal irradiation system. Build Environ 72: 116-124. 


\title{
$\&_{\mathrm{CSH}}^{\infty} \&$ Cold Spring Harbor

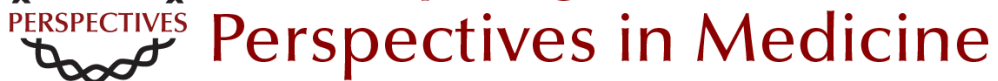

\section{Transmission and Institutional Infection Control of Tuberculosis}

\author{
Edward A. Nardell
}

Cold Spring Harb Perspect Med 2016; doi: 10.1101/cshperspect.a018192 originally published online August 20, 2015

\section{Subject Collection Tuberculosis}

Transmission and Institutional Infection Control of Tuberculosis Edward A. Nardell

Innate and Adaptive Cellular Immune Responses

to Mycobacterium tuberculosis Infection Katrin D. Mayer-Barber and Daniel L. Barber

Tuberculosis Comorbidity with Communicable and Noncommunicable Diseases

Matthew Bates, Ben J. Marais and Alimuddin Zumla

Host-Directed Therapies for Tuberculosis David M. Tobin

Immunity and Immunopathology in the Tuberculous Granuloma Antonio J. Pagán and Lalita Ramakrishnan

Tuberculosis Drug Development: History and Evolution of the Mechanism-Based Paradigm? Sumit Chakraborty and Kyu Y. Rhee

Genetic Approaches to Facilitate Antibacterial Drug Development Dirk Schnappinger

The Tuberculosis Drug Discovery and Development Pipeline and Emerging Drug Targets Khisimuzi Mdluli, Takushi Kaneko and Anna Upton
Clinical Aspects of Adult Tuberculosis Robert Loddenkemper, Marc Lipman and Alimuddin Zumla

Advances in Diagnostic Assays for Tuberculosis Stephen D. Lawn

Diagnosis and Management of Latent

Tuberculosis Infection

Laura Muñoz, Helen R. Stagg and Ibrahim Abubakar

Mycobacterial Growth Iria Uhía, Kerstin J. Williams, Vahid Shahrezaei, et al.

Multidrug-Resistant Tuberculosis and Extensively

Drug-Resistant Tuberculosis Kwonjune J. Seung, Salmaan Keshavjee and Michael L. Rich

The Mycobacterial Cell Wall--Peptidoglycan and

Arabinogalactan Luke J. Alderwick, James Harrison, Georgina S. Lloyd, et al.

Tuberculosis and HIV Coinfection Judith Bruchfeld, Margarida Correia-Neves and Gunilla Källenius

Imaging in Tuberculosis Jamshed B. Bomanji, Narainder Gupta, Parveen Gulati, et al.

For additional articles in this collection, see http://perspectivesinmedicine.cshlp.org/cgi/collection/ 